\title{
Evidence on the best way to perform oral hygiene with chlorhexidine in critically ill patients: systematic review and meta-analysis
}

\author{
JR Gnatta ${ }^{1}$, IRS Cabral de Menezes $^{2}$, RA Lacerda ${ }^{1 *}$ \\ From International Conference on Prevention \& Infection Control (ICPIC 2011) \\ Geneva, Switzerland. 29 June - 2 July 2011
}

\section{Introduction / objectives}

Although the scientific literature has demonstrated the relevance of oral hygiene with chlorhexidine (CHX) in the prevention of pneumonia, there is wide variation in the product, concentration, frequency, duration and technique application.

\section{Methods}

Systematic review and meta-analysis of articles in English, Spanish or Portuguese. Bases: Cochrane, EMBASE, Lilacs, PubMed/Medline, Ovid. Search: October to November 2010 using descriptors indexed. Question: are there evidence about the best way to perform oral hygiene with chlorhexidinefor prevention of respiratory infection in critically ill patients on mechanical ventilation?

\section{Results}

10 primary studies were grouped in 4 groups (G1-4) based in criteria of concentration of CHX. G1 (10 primary studies with different concentrations of $\mathrm{CHX}$ ) studies were homogeneous (Cochrane $\mathrm{Q}$ het $\mathrm{p}=0.35$ ) and the common $\mathrm{RR}$ was significative $(\mathrm{p}<0.001$ and $\mathrm{CI}=95 \%) ; \mathrm{G} 2$ (5 primary studies CHX $0.12 \%$ ) showed homogeneity (Cochrane $\mathrm{Q}$ het $\mathrm{p}=0.67$ ) and the use of CHX represented protection $(\mathrm{p}<0.05)$; The G3 (3 primary studies CHX $0.2 \%$ ) there was heterogeneity between studies $(\mathrm{p}=0.037)$ and $\mathrm{CHX}$ not represent a protective factor ( $\mathrm{p}>0.05$ ), G4 (2 primary studies CHX $2 \%$ ) homogeneous studies (Cochran $\mathrm{Q}$ het $\mathrm{p}=0.62)$ and use of CHX was significant $(\mathrm{p}=0.021<0.05)$.

${ }^{1}$ Nursing School, University of Sao Paulo, Sao Paulo, Brazil

Full list of author information is available at the end of the article

\section{Conclusion}

If seems no doubt about the protective effect of oral hygiene with $\mathrm{CHX}$ in preventing pneumonia in critically ill patients, there is no evidence for adoption of protocols to guide the $\mathrm{CHX}$ concentration, as well as duration, frequency and application technique.

\section{Disclosure of interest}

None declared.

\section{Author details}

${ }^{1}$ Nursing School, University of Sao Paulo, Sao Paulo, Brazil. ${ }^{2}$ Comission

Control Hospital Infection, University Hospital HU-USP, Sao Paulo, Brazil.

Published: 29 June 2011

doi:10.1186/1753-6561-5-S6-P72

Cite this article as: Gnatta et al:: Evidence on the best way to perform oral hygiene with chlorhexidine in critically ill patients: systematic review and meta-analysis. BMC Proceedings 2011 5(Suppl 6):P72.

Submit your next manuscript to BioMed Central and take full advantage of:

- Convenient online submission

- Thorough peer review

- No space constraints or color figure charges

- Immediate publication on acceptance

- Inclusion in PubMed, CAS, Scopus and Google Scholar

- Research which is freely available for redistribution 